\title{
The Identification of Atypical Strains of Pseudomonas aeruginosa
}

\author{
BY A. H. WAHBA* \\ The Cross-Infection Reference Laboratory, \\ Central Public Health Laboratory, London N.W.9 \\ AND J. H. DARRELL \\ The Department of Bacteriology, Postgraduate Medical School of \\ London, London W.12
}

(Received 1 September 1964)

\begin{abstract}
SUMMARY
The diversity of colonial types of Pseudomonas aeruginosa which may be encountered is described, together with a series of biochemical tests and the application of serological and pyocine typing which are of use in identifying atypical strains. These methods are particularly recommended for strains which do not form pigment. It is suggested that absence of pigment production even on special media does not preclude the possibility that a strain is $\boldsymbol{P}$. aeruginosa.
\end{abstract}

\section{INTRODUCTION}

Members of the genus Pseudomonas are widely distributed in nature, but the only common human pathogen is Pseudomonas aeruginosa. In the clinical laboratory, therefore, the practical problem is to distinguish $\boldsymbol{P}$. aeruginosa from other Pseudomonas species. The identification of typical strains of $P$. aeruginosa presents no difficulty, but the variability of the characteristics of this organism was recognized even in early work, the occurrence of non-pigment forming strains being particularly emphasized (Blanc, 1923; Cataliotti, 1935); Gaby \& Free (1953) stressed the importance of recognizing such strains in clinical material. These now appear to be occurring more frequently in hospital practice (Darrell \& Wahba, 1964). It has been suggested that the use of antibiotics may favour their occurrence (Seligmann \& Wassermann, 1947; Fujita, 1957; Schneierson, Amsterdam \& Perlman, 1960). Whether the increase in atypical strains is a true one, or merely results from an increasing interest in the group, their importance is not limited to clinical material and workers in many fields are faced with the problem of identifying such strains. Many techniques have been described for enhancing pigment production (Turfitt, 1936; Burton, Campbell \& Eagles, 1948; King, Ward \& Raney, 1954; Lutz, Schaeffer \& Hofferer, 1958; Frank \& De Moss, 1959; Rosenfeld \& Appel, 1963), but none has been widely used, mainly because of practical limitations on the number of different media routinely used in any laboratory. Pigment formation is usually not obvious on the blood agar used in clinical laboratories for primary cultures, and after overnight incubation may be absent. In practice, identification of $\boldsymbol{P}$. aeruginosa

* Present address: Department of Bacteriology, London School of Hygiene and Tropical Medicine, London W.C.1. 
is based initially on the characteristic colonial appearance and the typical smell. The variability of the former, in particular, is not generally recognized, and often identification is carried no further. In the present work, 1961 Pseudomonas strains from various sources were examined (Wahba, 1964a). A series of tests was developed, applied to 250 typical $\boldsymbol{P}$. aeruginosa strains (producing pyocyanin and smelling of trimethylamine) and found to give uniformly positive results. These tests were then applied to all $\boldsymbol{P}$. aeruginosa from human sources not producing pyocyanin, provisionally identified by a positive oxidase test and oxidative utilization of glucose in Hugh \& Leifson's medium, and also to a group of miscellaneous Pseudomonas strains from various sources. Six colonial variants were encountered.

\section{METHODS}

Organisms. The colonial appearances of 1961 Pseudomonas strains submitted for typing, or obtained from type culture collections and other sources, were examined; these were provisionally accepted as such on the grounds that they were oxidase-positive, motile, Gram-negative rods with oxidative use of glucose in Hugh \& Leifson's medium. Among them 1899 cultures were identified as Pseudomonas aeruginosa on the grounds either of being typical (producing pyocyanin and smell) or, when possessing atypical characters, by means of the series of tests described below. The following 272 Pseudomonas strains were selected for the present study. (a) Six strains, each representing one of the different colonial types of $P$. aeruginosa, (b) 185 strains from human sources which did not produce visible pigment on stock nutrient agar after incubation at $37^{\circ}$ for $24 \mathrm{hr}$ and 2 days at room temperature. (c) A miscellaneous group made up as follows: (i) 9 strains of $\boldsymbol{P}$. aeruginosa from various non-human sources (including a locust and a sample of barrier cream); (ii) 10 strains originally submitted under names other than $P$. aeruginosa, but thought as a result of our tests to be $P$. aeruginosa; (iii) 20 strains from human infections or environment submitted as $\boldsymbol{P}$. aeruginosa but found on testing to be other species of Pseudomonas and not further identified; (iv) 42 strains of Pseudomonas other than $\boldsymbol{P}$. aeruginosa.

Media. Stock nutrient agar No. 1 (Oxoid No. 1); Lab Lemco beef extract, 1 g.; yeast extract (Oxoid L 20), 2 g.; peptone (Oxoid L 37), 5 g.; sodium chloride, 5 g.; agar, 15 g.; distilled water to 1 1.; $\mathrm{pH} 7 \cdot 4$.

Nutrient agar No. 2 (Oxoid); Lab Lemco beef extract, $10 \mathrm{~g}$; peptone (Oxoid L 37), 10 g.; sodium chloride, 5 g.; 'Ionagar' No. 2, 10 g.; distilled water to 1 l.; pH $\mathbf{7} \cdot 4$.

Details of other media are given under techniques.

\section{Techniques}

Oxidase test. Rogers' (1963) modification of Kovàcs' (1956) method. Strains not growing at $37^{\circ}$ were incubated at $22^{\circ}$.

Motility. By microscopy of hanging drop.

Oxidation versus fermentation test of Hugh \& Leifson (1953).

Growth on nutrient agar No. 1 at $\mathbf{4 2}^{\circ}$ for three consecutive subcultures (Haynes, 1951, 1962). Slopes were incubated in a covered tin immersed in a $43^{\circ}$ water bath, thus ensuring that the actual temperature inside the culture tubes, as recorded 


\section{The identification of atypical strains of Pseudomonas aeruginosa 331}

by a thermometer in a blank tube, was in fact $42^{\circ}$. Control cultures were also incubated at $37^{\circ}$ and $22^{\circ}$.

Oxidation of potassium gluconate and production of slime within 3 days at $37^{\circ}$ and $42^{\circ}$. A modification of Haynes' (1951) original technique was used. The medium was dispensed in $5 \mathrm{ml}$. amounts and every strain was inoculated in duplicate, one tube being incubated at $37^{\circ}$ and the other at $42^{\circ}$ (to investigate the possibility of combining three tests for identifying Pseudomonas aeruginosa). The cultures were not shaken during incubation. After incubation for $48 \mathrm{hr}$ all tubes were examined for slime production by shaking. When slime was present, the cultures were then tested for reducing substances by adding half a 'Clinitest' tablet (Ames Co., Stoke Poges, Bucks, used for the estimation of sugar in urine) (Carpenter, 1961). When slime was absent, the culture was divided; one half was tested for the presence of reducing substance and the other incubated for a further 5 days at the appropriate temperature and re-examined. Strains not growing at $37^{\circ}$ were incubated at $22^{\circ}$.

Growth on $1 \%$ triphenyltetrazolium chloride in nutrient agar No. 1 (Selenka, 1958). 16 strains were inoculated per plate, the source of the inoculum being nutrient agar No. 1 slopes.

Growth on $\mathbf{0 . 2} \%(w / v)$ cadmium sulphate in nutrient agar No. 1 . This medium was modified from one containing cadmium chloride devised by Shkeir, Losse \& Bahn (1963).

Production of gelatinase by the plate method of Clarke (1953) with nutrient agar No. 1 as base and inoculating 16 strains per plate. Results read after $24 \mathrm{hr}$. Test repeated with negative strains and read after 3 days.

Production of collagenase. This was tested by a modification of the method devised by Oakley, Warrack \& van Heyningen (1946). Layered nutrient agar No. 1 plates were prepared, the upper layer containing $0.5 \%$ azocoll (hide powder coupled to a red azo dye). Sixteen strains were inoculated on each plate, incubated for 3 days and observed daily. The test was later performed by spotting melted azocollcontaining nutrient agar No. 1 on a basal layer of $2 \%$ agar in water and inoculating the solidified islets of medium with the strains.

Enhancement of pyocyanin production on a medium modified from Sierra (1957) and containing (g.): Bactopeptone, 10; sodium chloride, $5 ; \mathrm{CaCl}_{2} \mathrm{H}_{2} \mathrm{O}, 0.2 ; \mathrm{MgSO}_{4}$. $7 \mathrm{H}_{2} \mathrm{O}, 0 \cdot 1$; agar, 18 ; distilled water to 11 . Tween 80 solution, autoclaved separately, was added in a final concentration of $1 \% ; \mathrm{pH} 7 \cdot 4$. For comparative purposes, strains were also inoculated on nutrient agar No. 2 plates, as this medium improved the production of pyocyanin in some strains.

Production of pyocines (Hamon, 1956). This test apart from providing a means of typing $P$ seudomonas aeruginosa, appeared to give good results as a diagnostic procedure. Details of the procedure have been published (Wahba \& Lidwell, 1963; Darrell \& Wahba, 1964); briefly it consists of cross-streaking 12 indicator strains at right angles to the strain to be tested which had been previously killed with chloroform vapour and removed with a microscope slide.

Slide-agglutination with a polyvalent Pseudomonas aeruginosa antiserum. This was made by mixing 14 monospecific sera (Wahba, 1964b). Individual sera were produced in rabbits using 14 different serotypes; these included 12 types described by Habs (1957), type 13 (Sandvik, 1960) and type 14 (Wahba, 1964a). Saline suspensions made from overnight agar cultures were boiled for $2 \frac{1}{2} \mathrm{hr}$ and injected into 


\section{The identification of atypical strains of Pseudomonas aeruginosa 333}

rabbits in increasing volumes (from 0.1 to $2 \mathrm{ml}$.) on alternate days; the initial dose was given subcutaneously and the remainder intravenously in the ear vein. Strains for agglutination tests were taken from young cultures on nutrient agar plates or slopes (incubation $16 \mathrm{hr}$ or less). When the strain appeared to be autoagglutinable or mucoid it was plated on other media, especially pyocine-typing medium (Wahba, 1963), which decreased the formation of mucoid substance.

\section{RESULTS}

Colonial morphology. Six colonial types of Pseudomonas aeruginosa were observed. Their main features are summarized in Table 1 , which applies to colonies on nutrient agar No. 1 after incubation for $24 \mathrm{hr}$ at $37^{\circ}$, except for type 6 (dwarf) where the period of incubation was $48 \mathrm{hr}$. Typical examples of the six types are shown in Plate 1 (figs. 1-6); Table 2 gives the incidence of the various types among 1090 human strains.

The classical metallic sheen (Wahba, 1964c) was seen only with types 1,3 and 5; it may occur as small 'plaques', not to be confused with phage plaques (Warner, 1950). Mucoid colonies rapidly lose water and flatten on the medium giving a contoured or map-like appearance. There is considerable instability of colonial form on subculture; this is particularly marked with the gelatinous type (Schultz, 1947) which tends to lose many characteristics, but retains its firm adherence to the medium.

Table 2. Incidence of various colonial forms in 1090 strains of Pseudomonas aeruginosa from human material

$\%$

(a) Mixed S and SR, or $\mathbf{S}$ and $\mathbf{R}$, or $\mathbf{S}, \mathbf{S R}$ and $\mathbf{R}$,
or $\mathbf{S}$ and dwarf

$81 \cdot 3$ (the majority showing a predominantly $S$ type of colony)

(b) $\mathbf{R}$ form only $\quad \mathbf{1 6 \cdot 4}$

(c) Mucoid form only $\quad \mathbf{1 \cdot 2}$

(d) Gelatinous form only $0 \cdot 4$

(e) Dwarf form only $\quad 0 \cdot 7$

Growth requirements and biochemical reactions. The results obtained with the 185 Pseudomonas aeruginosa strains not forming pyocyanin on nutrient agar No. 1 and isolated from human sources were all uniform and corresponded to the pattern of the first strain in Table 3 (i) which was also the pattern of typical pyocyanin- or pyorubin-producing strains examined in the preliminary stages of this work. The results obtained with the miscellaneous group of organisms are shown in Table 3 (i-iv). The performance in the various tests of the strains grouped according to their final identification is given in Table 4.

Growth at $42^{\circ}$. Results given in Table 3 (i-iv) are for a single subculture as this is the usual routine in diagnostic laboratories. Although the test has been considered to be one of the most reliable features distinguishing Pseudomonas aeruginosa from other Pseudomonas species over $50 \%$ of the latter in our series were able to grow at this temperature on one occasion. They did not survive three subcultures (Haynes, 1962 ) but such a procedure would not be a practical routine test. 


\section{Typability} by serology
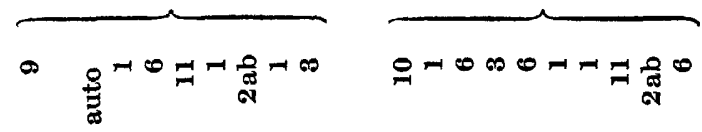

Typability by pyocine

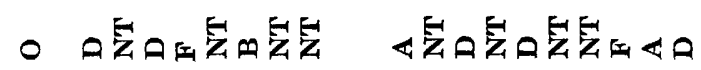

U.v.

fluorescence

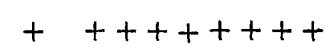

Pigment on special medium

\section{Collagenase}

密

\section{Gelatinase}

Growth on cadmium sulphate

Growth on

tetrazolium

Oxidation of $\Xi$

gluconate and slime

\section{Growth} at $37^{\circ}$

\section{Growth} at $42^{\circ}$ 
The identification of atypical strains of Pseudomonas aeruginosa 335

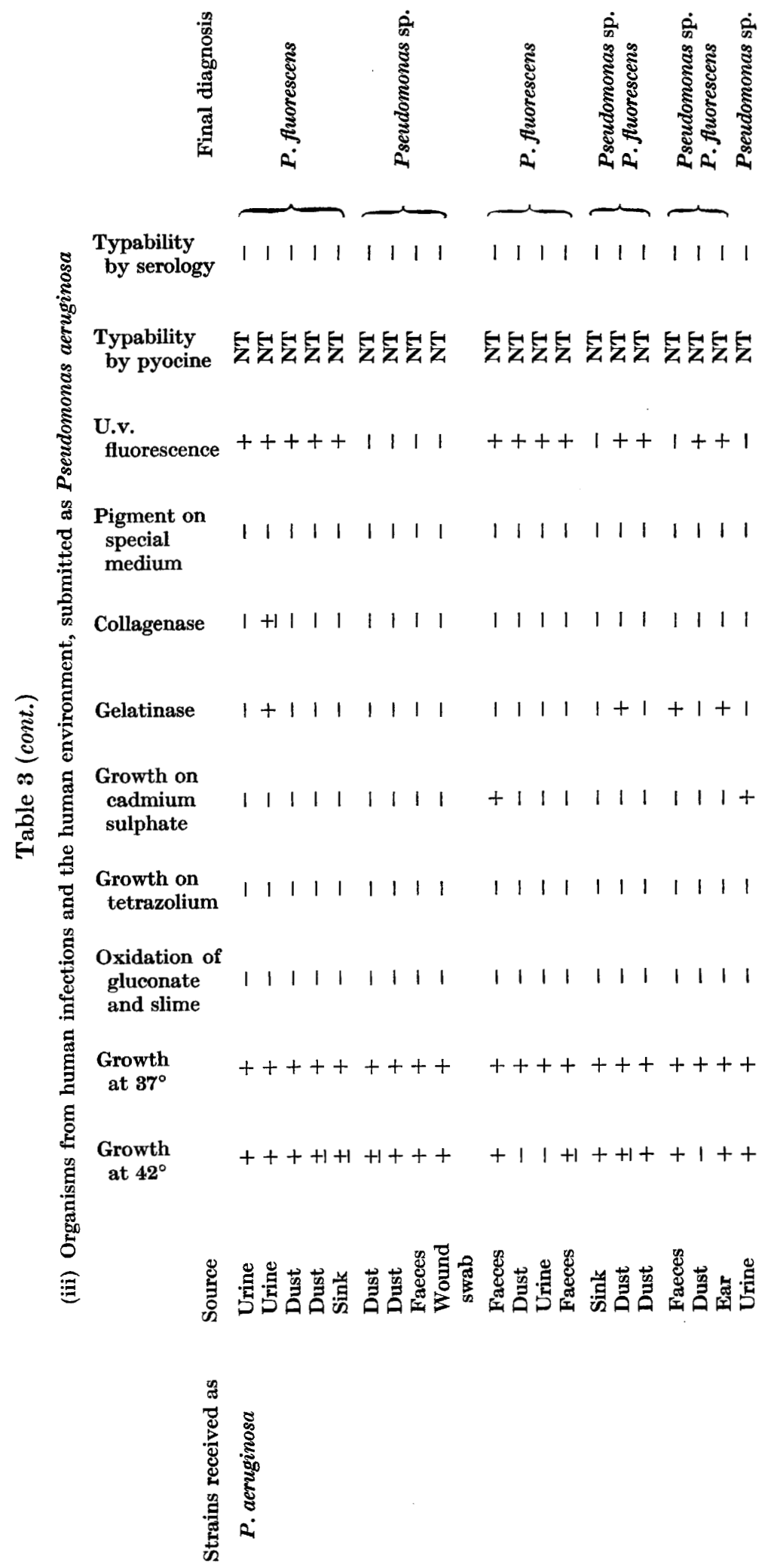




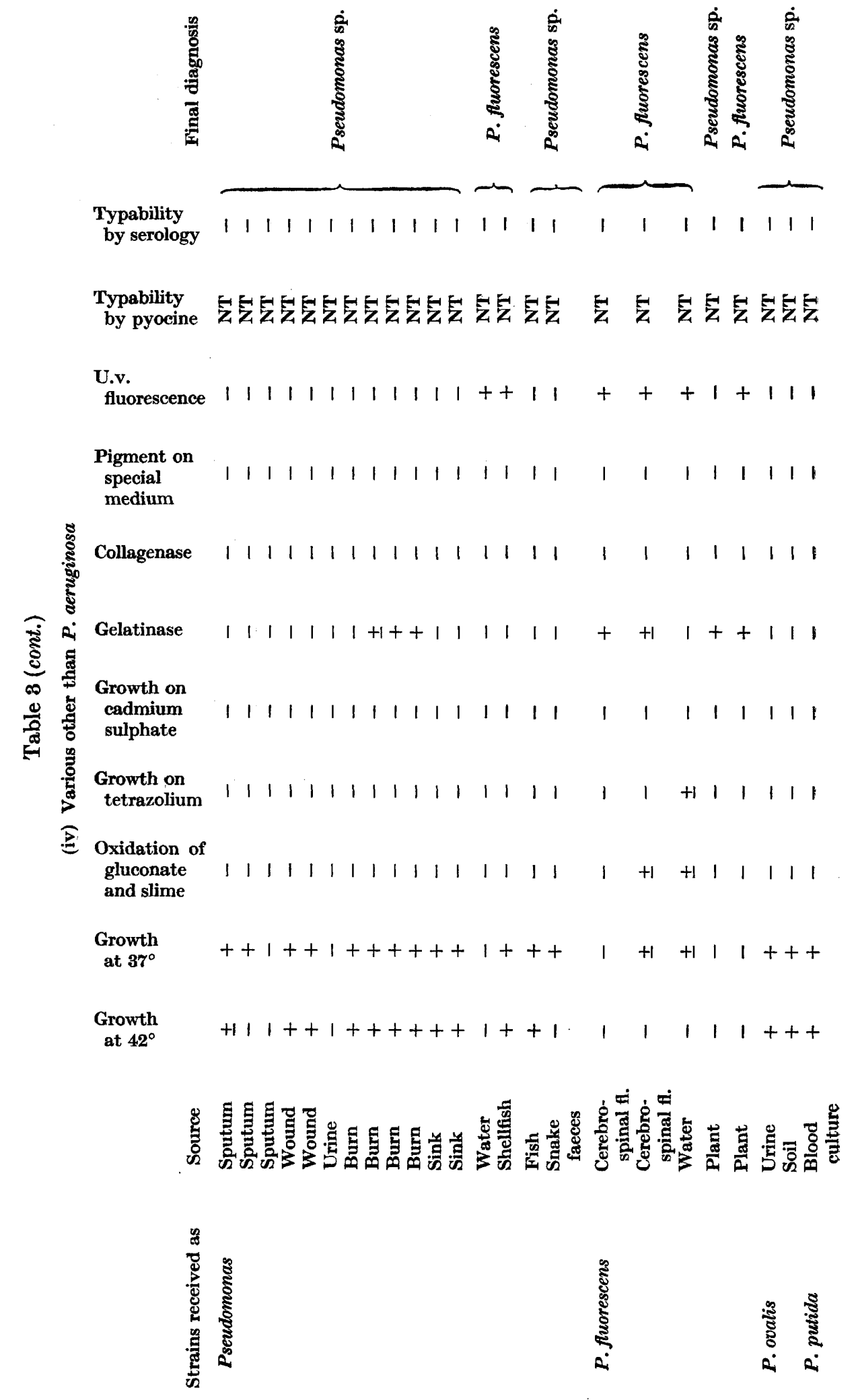


The identification of atypical strains of Pseudomonas aeruginosa 337
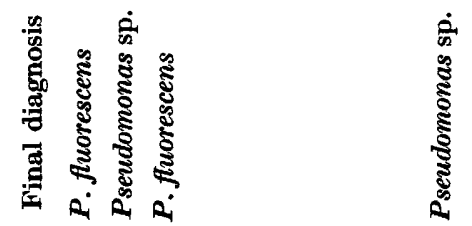

Typability

$\begin{array}{llllllllllllllllllll}\text { by serology } & 1 & 1 & 1 & 1 & 1 & 1 & 1 & 1 & 1 & 1 & 1 & 1 & 1 & 1 & 1 & 1 & 1 & 1\end{array}$

Typability
by pyocine

U.v.

fluorescence $+1+1 \quad 1 \quad 11111111111111$

Pigment on

special

medium

$\begin{array}{lllllllllllllllllll}\text { Collagenase } & \mid & 1 & +1 & 1 & 1 & 1 & 1 & 1 & 1 & 1 & 1 & 1 & 1 & 1 & 1 & 1 & 1 & 1\end{array}$

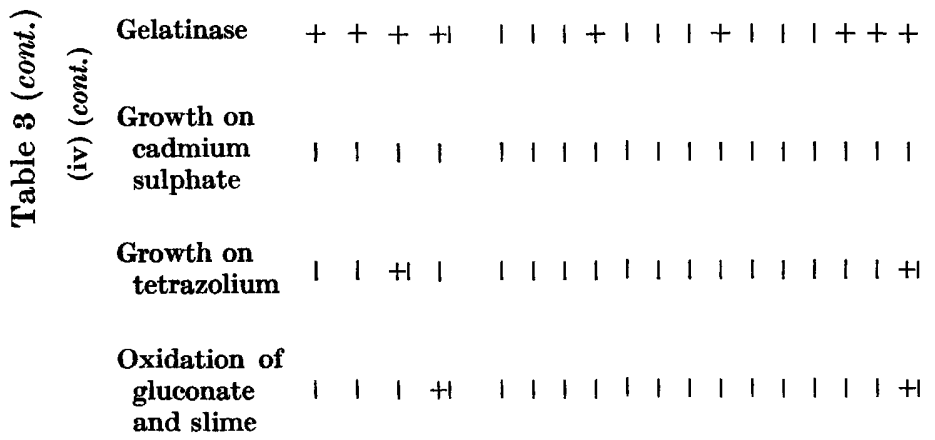

$\underset{\text { at } 37^{\circ}}{\operatorname{Growth}} \quad 1 \quad 1++11++111++1111+$

Growth at $42^{\circ}$

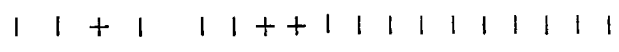
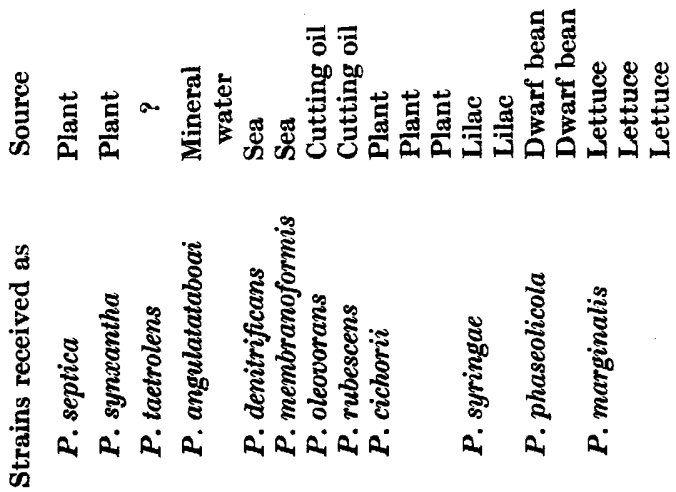
Growth at $37^{\circ}$. While a temperature optimum of less than $37^{\circ}$ is a strong indication that a strain is not Pseudomonas aeruginosa, the converse is not true. Table 4 shows that a high proportion of our other Pseudomonas cultures (45 of 62) also grew well at this temperature.

Oxidation of gluconate and slime production. This test proved more useful but is time-consuming; four strains other than Pseudomonas aeruginosa (see Table 4) gave positive results. Performance of the test at $42^{\circ}$ rendered it more specific for $\boldsymbol{P}$. aeruginosa.

Table 4. Summary of results of eleven tests on the miscellaneous group (c) organisms arranged according to their final identification on the basis of the scheme described

\begin{tabular}{|c|c|c|c|c|c|c|}
\hline & Total & $\begin{array}{l}\text { Growth } \\
\text { at } \mathbf{4 2} \mathbf{2}^{\circ}\end{array}$ & $\begin{array}{l}\text { Growth } \\
\text { at } 37^{\circ}\end{array}$ & $\begin{array}{l}\text { Oxidation } \\
\text { of glucon- } \\
\text { ate and slime } \\
\text { production }\end{array}$ & $\begin{array}{l}\text { Growth on } \\
\text { tetra- } \\
\text { e zolium } \\
\text { medium }\end{array}$ & $\begin{array}{l}\text { Growth on } \\
\text { cadmium } \\
\text { sulphate } \\
\text { medium }\end{array}$ \\
\hline P. aeruginosa & 19 & 19 & 19 & 19 & 19 & 18 \\
\hline P. fluorescens & 21 & 12 & 17 & 2 & 2 & 1 \\
\hline \multirow{2}{*}{$\begin{array}{l}\text { Other Pseudomonas } \\
\text { (not further identified }\end{array}$} & 41 & 22 & 28 & 2 & 1 & 1 \\
\hline & Gelatinase & Collagenase & $\begin{array}{c}\text { Pyocyani } \\
\text { or pyorubi } \\
\text { on specia } \\
\text { medium }\end{array}$ & $\begin{array}{l}\text { in } \\
\text { in } \\
\text { escence }\end{array}$ & $\begin{array}{c}\text { Typability } \\
\text { by } \\
\text { pyocine }\end{array}$ & $\begin{array}{c}\text { Typability } \\
\text { by } \\
\text { serology }\end{array}$ \\
\hline P. aeruginosa & 19 & 16 & 19 & 19 & 11 & 18 \\
\hline P. fluorescens & 8 & $2( \pm)$ & - & 21 & - & 一 \\
\hline Other Pseudomonas & 12 & 一 & - & - & - & - \\
\hline
\end{tabular}

Growth in the presence of cadmium sulphate and on tetrazolium media. These media were selective for Pseudomonas aeruginosa which, with very few exceptions, produced normal growth on both. Occasionally other Pseudomonas cultures also produced good growth but all other bacterial species were completely inhibited. In addition to its selective properties, cadmium sulphate medium enhanced fluorescin production by $\boldsymbol{P}$. aeruginosa.

Production of proteinases. Gelatinase activity is shared by many other members of the Pseudomonas genus (Table 4), and is of little differential importance. Marked collagenase activity is found only in strains of Pseudomonas aeruginosa; it was observed twice only among other Pseudomonas cultures and in both the reaction was very weak. A positive reaction is of value in identifying an organism as $P$. aeruginosa, but 3 of 19 strains were negative.

Enhancement of pigment production. One hundred and eighty-five strains (17\%) from a total of 1090 Pseudomonas aeruginosa cultures isolated from human material did not produce pigment on nutrient agar No. 1 after overnight incubation followed by a period of 2 days at room temperature. Various pigment-enhancing media were tested. Table 5 shows the types of pigment produced by these 185 strains on nutrient agar No. 2 and on the modified Sierra medium finally adopted. Nutrient agar No. 2 which contains more peptone and meat extract than nutrient agar No. 1, gave appreciably better results, but $\mathbf{5 7}$ strains still did not show pigment, as against only 34 ( $3 \%$ of the total) on the modified Sierra medium. The latter has the added advantage of stimulating early pigment formation in nearly every case (i.e. after 


\title{
The identification of atypical strains of Pseudomonas aeruginosa 339
}

overnight incubation) whereas with nutrient agar No. 2 an appreciable number of strains still required incubation for $48 \mathrm{hr}$ to show pigment production. When strains produced fluorescent pigment only, this was detectable on this medium under ultraviolet radiation, although no yellow-green colour was apparent to the naked eye.

Ultraviolet fuorescence. The method of Lowbury, Lilly \& Wilkins (1962) was used, but as will be seen from Table 3, it did not distinguish Pseudomonas aeruginosa from $P$. fluorescens.

Production of pyocines. Production of pyocines against a set of indicator strains provided additional confirmatory evidence that an organism is $\boldsymbol{P}$ seudomonas aeruginosa. In a series of 1090 strains (Darrell \& Wahba, 1964), 7.6\% did not produce pyocines. However, strains of $\boldsymbol{P}$. aeruginosa which do not type by both pyocine production and the serological method are very rare.

Use of polyvalent agglutinating serum. Of the series of 1899 strains of $\boldsymbol{P}_{\text {seudomonas }}$ aeruginosa, only 8,4 of which were ' $R$ ' forms, did not agglutinate. Cross-agglutination with $\boldsymbol{P}$. fluorescens did not occur with the pooled polyvalent serum, and even with undiluted component sera, cross-agglutination was very infrequent.

\section{Table 5. Pigment production by strains of Pseudomonas aeruginosa}

\author{
Production of pigment within $24 \mathrm{hr}$ at $37^{\circ}$ by 185 strains not showing pigment at $24 \mathrm{hr}$ \\ on stock nutrient agar medium.

$\begin{array}{lcc} & \begin{array}{c}\text { Nutrient agar } \\ \text { No. 2 }\end{array} & \begin{array}{c}\text { Modified Sierra } \\ \text { medium }\end{array} \\ \text { Blue-green } & \mathbf{3 3}(18 \%) & \mathbf{6 6}(\mathbf{3 5} \%) \\ \text { Yellow-green } & \mathbf{8 3}(\mathbf{4 5} \%) & \mathbf{7 2}(\mathbf{3 9} \%) \\ \text { Red or brown } & \mathbf{1 2}(\mathbf{7} \%) & 13(7 \%) \\ \text { No pigment* } & \mathbf{5 7}(\mathbf{3 0} \%) & \mathbf{3 4}(\mathbf{1 9} \%)\end{array}$ \\ * Included here on the strength of their reactions with other tests described.
}

\section{DISCUSSION}

Williamson (1956) stated that a single morphological description for Pseudomonas aeruginosa was inadequate. In the present paper, six colonial types are described and it is essential to be aware of this possible range of colonial forms if atypical cultures are to be correctly identified. We have used existing names for types previously described (Gaby, 1955; Köhler, 1958; Schultz, 1947), typical colonies being designated smooth in spite of their matt surface, and the smooth variant, resembling the colonies of Enterobacteriaceae, being called the S-R (smooth-rough) type. Apart from these and the rough, mucoid and gelatinous types previously described, a new form, the dwarf type, is described. It requires $48 \mathrm{hr}$ to produce visible growth and would be missed in many clinical laboratories. Variants commonly occur in one and the same culture (Zierdt \& Schmidt, 1964) giving the false impression that different bacterial species are present. Mucoid colonies cause confusion, being usually non-pigmented, and resembling colonies of Enterobacter aerogenes and Klebsiella species, from which however, they may be distinguished by the Kovàcs oxidase test. The oxidase reaction is the single most useful screening test for growth from any media. A negative reaction excludes all types of Pseudomonas 
encountered in human material (some oxidase-negative species are known, such as $\boldsymbol{P}$. maltophila and some plant pathogens), while an immediate strongly positive reaction is highly suggestive that the organism belongs to this group. Oxidasepositive cultures require confirmatory testing with Hugh \& Leifson's medium or for arginase activity (Sherris et al. 1959; Taylor \& Whitby, 1964), but both these tests establish only that the strain belongs to the genus Pseudomonas. The final differentiation of $\boldsymbol{P}$. aeruginosa from other Pseudomonas species is a matter of considerable difficulty. The salient distinguishing feature of the species is the production of pyocyanin or pyorubin and to induce its formation by atypical strains probably remains the most satisfactory method of identifying these. For this purpose, the modified Sierra medium is the most efficient of those tested, with regard to the number of strains which produce pigment and to the rapidity of its appearance. The pigments produced also show a range of colours not fully appreciated in clinical practice in spite of the work by Gessard $(1919,1920)$.

Agglutination by a polyvalent serum against Pseudomonas aeruginosa strains is a very specific test, but of less general application unless large-scale production of the sera became feasible.

In applying the other tests to a selected series of atypical strains, a different pattern of results was obtained with strains in which pigment production could be induced, from the pattern given by the majority of persistently non-pigmentforming strains. Pigment-producing strains grew on cadmium- and tetrazoliumcontaining media, produced collagenase and in the majority of cases also produced pyocines active against typing strains. They also had a higher temperature optimum and oxidized gluconate with slime production. This pattern of reaction also occurred in a small proportion of persistently non-pigment-forming organisms, constituting 3\% of all Pseudomonas aeruginosa strains examined. The pattern appears to be specific for $\boldsymbol{P}$. aeruginosa and we believe that such strains represent truly nonpigment-producing strains of this species. With some atypical strains it may be necessary to test all the eleven properties. The tests for growth on cadmium and tetrazolium media are the simplest and most likely to find routine application.

In conclusion, we recommend the following procedure to identify atypical Pseudomonas aeruginosa cultures. First, ascertain that the strain is a Pseudomonas; this is done by examining shape and staining reaction: Gram-negative rod, test for motility by hanging drop: motile, except for mucoid strains, perform the oxidase reaction: immediate positive, test with Hugh \& Leifson's medium : oxidative use of glucose and examine for arginase activity: positive. Then proceed with the tests which will prove the identity of $P$. aeruginosa: growth at $42^{\circ}$, at $37^{\circ}$, oxidation of gluconate or production of slime, production of pyocyanin or pyorubin on Sierra's modified medium, growth on tetrazolium and cadmium containing media, production of collagenase, fluorescence under ultraviolet radiation, production of pyocines and slide-agglutination with a polyvalent serum.

We are grateful to Professor Mary Barber and Dr M. T. Parker for their valuable help and suggestions. Our thanks are due to $\mathrm{Mr}$ W. Brakenbury and Mr C. J. Webb for the photographs. 


\section{The identification of atypical strains of Pseudomonas aeruginosa 341}

\section{REFERENCES}

Blanc, J. (1923). Transformation des bacilles pyocyaniques en bacilles sans pigment. Essai d'interprétation. C.r. Séanc. Soc. Biol. 88, 52.

Burton, M. O., Campbell, J. J. R. \& Eagles, B. A. (1948). The mineral requirements for pyocyanin production. Can. J. Res. (C), $26,15$.

Carpenter, K. P. (1961). The relationship of the Enterobacterium A 12 (Sachs) to Shigella Boydii 14. J. gen. Microbiol. 26, 535.

Catalioti, F. (1935). Ricerche sul B. pyocyaneum. G. Batt. Immunol. 15, 161.

Clakke, S. K. R. (1953). A simplified plate method for detecting gelatine-liquefying bacteria. J. clin. Path. 6, 246.

Danz, F. J. \& Schultz, E. W. (1949). Gelatinous variants of Pseudomonas aeruginosa. J. Bact. 58, 367.

Darreli, J. H. \& Wahba, A. H. (1964). Pyocine typing of hospital strains of P. pyocyanea. J. clin. Path. 17, 236.

Frank, L. H. \& DE Moss, R. D. (1959). On the biosynthesis of pyocyanin. J. Bact. 77, 776 .

FuJITA, H. (1957). Influence of antibiotics on the production of pyocyanin and fluorescin by $\boldsymbol{P}$. aeruginosa and the occurrence of non-pyocyanin strains from clinical specimens. Mie. Med. J. 7, 169.

GABY, W. L. (1955). Taxonomic problems relating to the identification of species within the genus Pseudomonas. Int. Bull. bact. Nomencl. Taxon. 5, 153.

GABY, W. L. \& FrEe, E. (1953). Occurrence and identification of non-pigmented strains of $P$. aeruginosa in the clinical laboratory. J. Bact. 65, 746.

Gessard, C. (1919). Classement des germes pyocyaniques par les pigments. C.r. Séanc. Soc. Biol. 82, 795.

Gessard, C. (1920). Technique d'identification des germes pyocyaniques. Ann. Inst. Pasteur, 34, 88.

HaBS, I. (1957). Untersuchungen über die O-Antigene von $P$. aeruginosa. $Z$. Hyg. InfektKr. 144, 218.

Hamon, Y. (1956). Contribution à l'étude des pyocines. Ann. Inst. Pasteur, 91, 82.

Haynes, W. C. (1951). Pseudomonas aeruginosa characterization and identification. J. gen. Microbiol. 5, 939.

HAYNES, W. C. (1962). Comparative taxonomy of crystallogenic strains of $P$. aeruginosa and $P$. chlororaphis. J. Bact. 84, 1080.

Henriksen, S. D. (1948). Some unusual mucoid organisms. Acta path. microbiol. scand. 25,485 .

Hugh, R. \& Leifson, E. (1953). The taxonomic significance of fermentative versus oxidative metabolism of carbohydrates by various Gram-negative bacteria. J. Bact. 66, 24.

King, E. O., Ward, M. K. \& Raney, D. E. (1954). Two simple media for the demonstration of pyocyanin and fluorescin. J. lab. clin. Med. 44, 301.

Köhler, W. (1958). Pseudomonas aeruginosa: Cytologie, Biochemie und Serologie. Wiss. Z. Univ. Rostock, 7, 25.

Kovìcs, N. (1956). Identification of $P$. pyocyanea by the oxidase reaction. Nature, Lond. $178,703$.

Lowbury, E. J. L., Lilly, H. A. \& Wilkins, M. D. (1962). A cabinet for the detection of fluorescent bacterial cultures. J. clin. Path. 15, 339.

Lutz, A., Schaeffer, A. \& Hofferer, M. J. (1958). Caractères biologiques et sensibilité aux antibiotiques de bacilles du genre Pseudomonas. Ann. Inst. Pasteur, 95, 49.

Munoz, J. \& Dougherty, W. J. (1951). Studies on a mucoid strain of Pseudomonas aeruginosa and its smooth variant. Bact. Proc. p. 73.

Oakley, C. L., Warrack, G. H. \& van Heyningen, W. E. (1946). The collagenase ( $\kappa$-toxin) of Clostridium welchii type A. J. Path. Bact. 48, 229.

ROGERS, K. B. (1963). Lancet, 2, 682 (Letter).

Rosenfeld, J. \& APPEL, G. (1963). The use of neopeptone glycerol agar for the identification of P. aeruginosa. Am. J. med. Techn. 29, 189. 
SANDvik, O. (1960). Serological comparison between strains of $P$. aeruginosa from human and animal sources. Acta path. microbiol. scand. 48, 56.

Schneierson, S. S., Amsterdam, D. \& Perlman, E. (1960). Inhibition of P. aeruginosa pigment formation by chloramphenicol and erythromycin. Antibiotics Chemother. 10, 30.

Schultz, E. W. (1947). A gelatinous variant of P. aeruginosa. Proc. Soc. exp. Biol. Med. 65, 289.

Schwarz, L. H. \& Lazarus, J. A. (1947). An unusual strain of Pseudomonas aeruginosa. J. Bact. 54, 30.

Selenka, F. (1958). Über die Abgrenzung von $P$. aeruginosa gegen $P$. fluorescens und $P$. putida auf TTC Nährböden. Arch. Hyg. 142, 569.

SeligmanN, E. \& WassermanN, M. (1947). Induced resistance to streptomycin. J. Immunol. 57, 351.

Sherris, J. C., Shoesmith, J. G., Parker, M. T. \& Breckon, D. (1959). Test for the rapid breakdown of arginine by bacteria: Their use in the identification of pseudomonads. J. gen. Microbiol. 21, 389.

Shkeir, I. L., Losse, F. L. \& BAHN, A. N. (1963). The isolation and incidence of P. aeruginosa from human saliva. Bact. Proc. p. 71.

Sierra, G. (1957). A simple method for the detection of lipolytic activity of microorganisms and some observations on the influence of the contact between cells and fatty substrates. Antonie van Leeurvenhoek, 23, 15.

Sonnenschein, C. (1927). Die Mucosus-Form des Pyocyaneus Bakteriums, Bacterium pyocyaneum mucosum. Ein Beitrag zur experimentellen Bakterienvariation. $\mathbf{Z b l}$. Bakt. (I. Abt. Orig.) 104, 365.

TAYloR, J. J. \& Whitby, J. L. (1964). Pseudomonas pyocyanea and the arginine dihydrolase system. J. clin. Path. 17, 122.

TURFITT, G. E. (1926). Bacteriological and biochemical relationships in the pyocyaneusfluorescens group I. The chromogenic function in relation to classification. Biochem. $J$. 30, 1323.

WAHBA, A. H. (1963). The production and inactivation of pyocines. J. Hyg., Camb. 61, 431.

WAHBA, A. H. (1964a). Thesis. University of London.

WaHBa, A. H. (1964b). Hospital infection with Pseudomonas pyocyanea: an investigation by combined pyocine and serological typing. B.M.J. (in the Press).

Waнba, A. H. $(1964$ c). Metallic sheen in Pseudomonas aeruginosa. Nature, Lond. 204, 502.

WAHBA, A. H. \& LidWell, O. M. (1963). A simple apparatus for colicine typing. J. appl. Bact. 26, 246.

Warner, P. T. J. C. P. (1950). The iridescent phenomenon of P. pyocyanea. Br. J. exp. Path. 31, 242.

WrLliamson, C. K. (1956). Morphological and physiological considerations of colonial variants of $P$. aeruginosa. J. Bact. 71, 617 .

Zierdt, C. H. \& Schmidt, P. J. (1964). Dissociation in Pseudomonas aeruginosa. J. Bact. 87, 1003.

\section{EXPLANATION OF PLATE}

Representative colonial variants of Pseudomonas aeruginosa after $24 \mathrm{hr}$ incubation at $37^{\circ}$ except for Type 6 which requires $48 \mathrm{hr}$ to produce visible growth. All colonies are from nutrient agar No. 1 cultures.

(1) ' $\mathrm{S}$ ' (smooth) Type $\times 10$

(3) 'R' (Rough) Type X10

(5) Gelatinous Type X10
(2) 'SR' (smooth-rough) Type X 10

(4) Mucoid Type X10

(6) Dwarf Type X10 

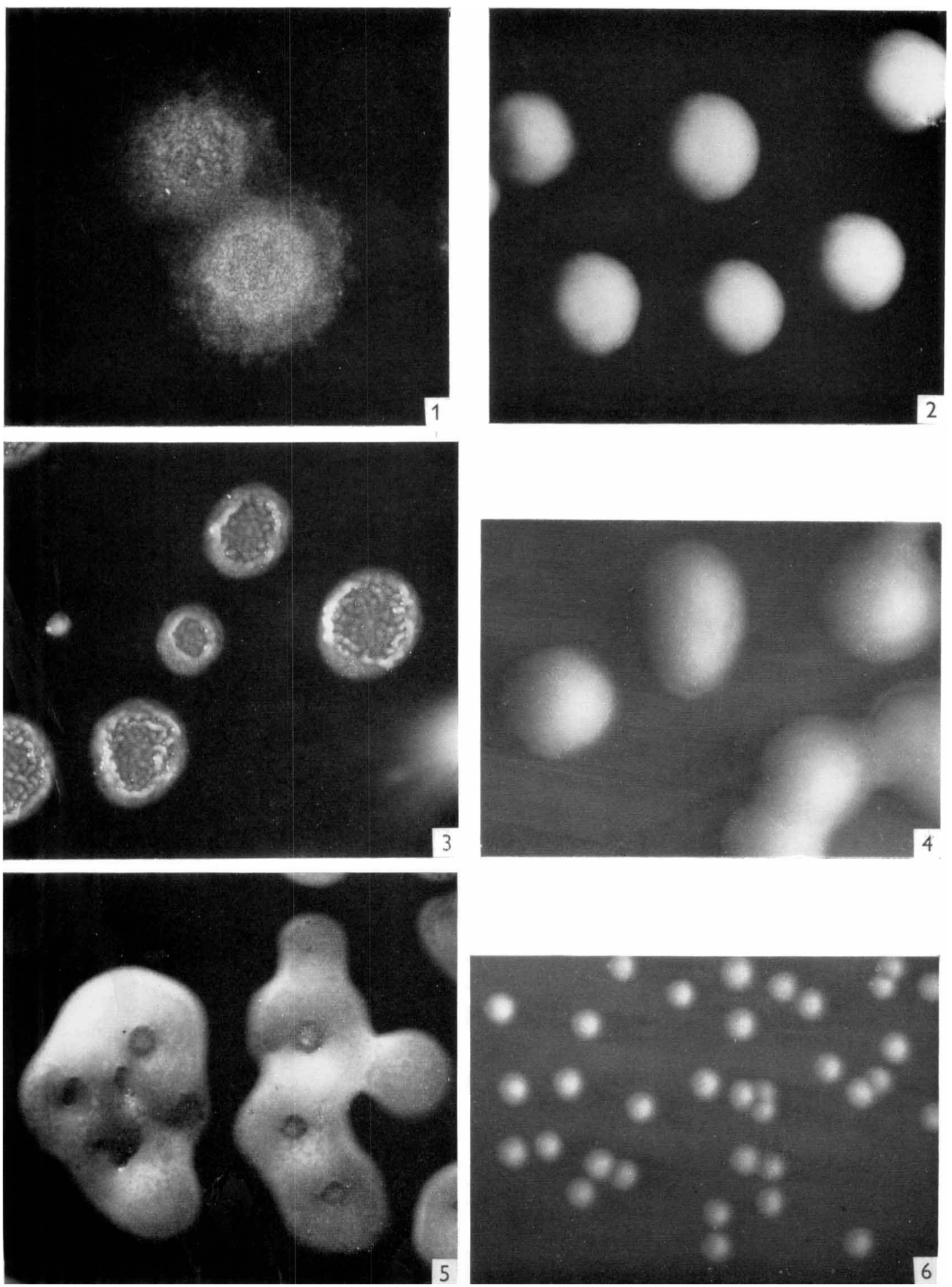

A. H. WAHBA AND J. H. DARRELL

(Facing p. 342) 
